\title{
Europe : vers un profil européen pour la formation des enseignants de langues étrangères?
}

Le point sur...

\section{William McEvoy}

\section{(2) OpenEdition}

\section{Journals}

Édition électronique

URL : http://journals.openedition.org/ries/1420

DOI : $10.4000 /$ ries. 1420

ISSN : 2261-4265

\section{Éditeur}

Centre international d'études pédagogiques

Édition imprimée

Date de publication : 1 septembre 2004

Pagination : 17-18

ISBN : 978-2-85420-561-8

ISSN : 1254-4590

Référence électronique

William McEvoy, «Europe : vers un profil européen pour la formation des enseignants de langues

étrangères ? », Revue internationale d'éducation de Sèvres [En ligne], 36 | septembre 2004, mis en ligne le 18 novembre 2011, consulté le 19 avril 2019. URL : http://journals.openedition.org/ries/1420 ; DOI : $10.4000 /$ ries. 1420

Ce document a été généré automatiquement le 19 avril 2019

(C) Tous droits réservés 


\title{
Europe : vers un profil européen pour la formation des enseignants de langues étrangères?
}

\author{
Le point sur...
}

William McEvoy

1 Le plan d'action de la Commission européenne pour «promouvoir l'apprentissage des langues et la diversité linguistique en Europe » a fortement insisté sur la formation des enseignants de langues étrangères, dont le rôle est crucial dans la création d'une Europe plurilingue et pluriculturelle. Un projet de recherche en ce sens, financé par la Commission, est actuellement en cours à l'université de Southampton au Royaume-Uni ${ }^{1}$. Son objectif principal est d'élaborer un profil pour la formation des enseignants de langues étrangères. Il s'agit de développer un vocabulaire commun et cohérent pour définir les valeurs et les priorités de cette formation à l'échelon européen, tout en tenant compte des nombreuses différences nationales et régionales. Promouvoir une coopération approfondie et des échanges multilatéraux, créer des réseaux de communication réels et virtuels, faciliter la mobilité des enseignants européens sont les principes fondateurs du profil. «Travailler ensemble » ne signifiant pas «faire la même chose partout", le profil est conçu comme une boîte à outils dans laquelle les responsables de la formation des futurs enseignants en langue pourront puiser des idées, des indications et des conseils.

2 La première partie de la recherche, achevée en 2002, a abouti à un livre, L'Enseignant européen de langues étrangères ${ }^{2}$, qui dresse le bilan des voies de formation disponibles pour les futurs enseignants dans une trentaine de pays européens. Étant donné les divergences dont il témoigne, l'idée d'un profil commun conçu comme un cadre de référence aussi bien pour les décideurs des systèmes éducatifs que pour les éducateurs d'enseignants, est née. Au cours de cette deuxième étape, l'équipe de recherche s'est concentrée sur deux axes d'enquête : d'abord sur les acquis, les compétences et les ressources fondamentaux pour l'enseignement des langues étrangères en Europe, ensuite sur les valeurs et les 
attitudes que les enseignants de langues étrangères devraient être encouragés à adopter et à promouvoir au cours de leur vie professionnelle.

3 Aujourd'hui, le profil se divise en trois sections. Il commence par la structure générale des programmes de formation avant de passer au contenu des programmes et aux stratégies que le futur enseignant devrait apprendre et être capable d'intégrer à ses cours. Enfin, le profil souligne les valeurs culturelles, sociales et civiques que doivent promouvoir l'enseignant et l'enseignement des langues étrangères en Europe.

Afin d'approfondir le profil, trois étapes de recherche ont été définies.

5 Un groupe d'experts européens a d'abord été réuni. Son rôle était d'examiner le profil d'un point de vue épistémologique et linguistique. Ensuite, une douzaine de praticiens européens de la formation des enseignants de langues étrangères ont participé à un questionnaire suivant la méthodologie Delphi, dont les trois étapes visent à atteindre un consensus. La richesse et la variété des réponses ont montré l'importance de la flexibilité du profil, qui doit se montrer capable de s'adapter aux exigences régionales et nationales, ainsi que la nécessité de privilégier le rôle des tuteurs dans la formation des enseignants de langues étrangères.

onze études de cas ont été menées dans une variété d'institutions européennes choisies selon des critères divers. Cet échantillon a permis de fournir des exemples de bonnes pratiques et d'identifier les problèmes que rencontre une institution désireuse d'améliorer son programme de formation.

7 Les résultats de ces trois volets de recherche aboutiront à plusieurs documents de référence. Le profil lui-même existera en deux versions: un profil de base, qui comportera une liste des éléments jugés essentiels aux programmes de formation et, en parallèle, une version accompagnée d'explications, de précisions, de commentaires d'experts et d'illustrations tirées d'études de cas. En outre, une série d'indications visant à garantir la qualité sera formulée au terme de la consultation avec le réseau d'experts.

Un plan d'action pour la diffusion et la mise en place du profil européen est en cours d'élaboration, à travers notamment le réseau d'experts de l'équipe de l'université de Southampton, l'accès aux résultats de l'enquête sur le site Internet ${ }^{3}$ et la publication d'une brochure. L'idée d'un schéma de pilotage destiné à six institutions européennes qui s'engageraient à intégrer les éléments du profil à leurs programmes de formation d'enseignants de langues étrangères est par ailleurs étudiée.

\section{NOTES}

1. L'équipe de recherche est dirigée par le professeur Michael Kelly. Voir Revue internationale d'éducation de Sèvres $n^{\circ} 33$, septembre 2003, «l'enseignement des langues vivantes à l'étranger, enjeux et stratégies), pp. 65-75.

2. Michael Grenfell, Michael Kelly and Diana Jones, The European Language Teacher. Peter Lang, 2003.

3. www.lang.ston.ac.uk/profile 
INDEX

\section{Index géographique : Europe}

Mots-clés : formation des enseignants, enseignement des langues, Commission européenne, politique européenne

\section{AUTEUR}

\section{WILLIAM MCEVOY}

Université de Southhampton. 